\title{
IMPLICACIONES DEL DIÁLOGO EN LA ENSEÑANZA: DE LA NEGOCIACIÓN A LA CREACIÓN DE CULTURA
}

\author{
IMPLICATIONS OF DIALOGUE IN TEACHING: FROM NEGOTIATION TO CREATING CULTURE
}

\author{
Rafael Correia Lima1
}

Submetido em: 22/04/2020

Correções requeridas em: 25/05/2020

Aprovado em: 14/09/2020

\section{RESUMEN}

La investigación es un recorte de la tesis doctoral, "análisis de los diálogos como práctica pedagógica en la enseñanza: la relación desarrollada por los docentes y estudiantes", aprobada en la Universidad Nacional de Rosario, que hace discusiones del capítulo, el lenguaje en la educación, desarrollado por Jerome Bruner (1985), en su planteo trató de las implicaciones de negociación del lenguaje. El objetivo de la investigación es analizar el alcance de los conceptos del autor, complementándolos y poniendo a prueba para enfatizar soluciones prácticas de negociación que no contempla en su teoría. El referencial teórico charla con el autor Burbules (1999), Habermas (1976), Searle (1962) y Grice (1989). Es un estudio teórico que presenta una síntesis del diálogo en la enseñanza, las principales implicaciones del lenguaje de la educación, la negociación y las reglas del juego en el lenguaje que abarcan los hallazgos de la práctica escolar, desde la negociación a la creación de cultura planteada por el autor.

PALABRAS CLAVE: El lenguaje en la educación. La negociación. La creación de cultura.

\section{ABSTRACT}

The research is a cut of the doctoral thesis, "analysis of dialogues as pedagogical practice in teaching: the relationship developed by teachers and students", approved at the National University of Rosario, which makes discussions of the chapter, language in education, developed by Jerome Bruner (1985), in his field he addressed the implications of language negotiation. The aim of the research is to analyze the scope of the author's concepts, complementing them and testing them to emphasize practical negotiating solutions that he does not contemplate in his theory. The theoretical reference talks with author Burbules (1999), Habermas (1976), Searle (1962) and Grice (1989). It is a theoretical study that presents a synthesis of dialogue in teaching, the main implications of the language of education, negotiation and the rules of the game in language that encompass the findings of school practice, from negotiation to the creation of culture posed by the author.

KEYWORDS: Language in education. Negotiation. Creation of culture

\footnotetext{
${ }^{1}$ Graduado em Educação Artística na UBC Universidade Braz Cubas (2007); Graduado em Pedagogia na UNINOVE Universidade Nove de Julho (2009); Pós-graduado lato sensu em Pedagogia Hospitalar na FAMESP Faculdade Método de São Paulo (2013); Pós-graduado stricto sensu com título de Mestre em Ciências da Educação na UNIBE-PARAGUAY Universidad IberoAmericana (2017); Pós-graduado lato sensu em Especialização em Educação Profissional Integrada à Educação Básica na Modalidade Educação de Jovens e Adultos - PROEJA no IFSP Instituto Federal de Educação, Ciência e Tecnologia de São Paulo (2017); Pós-graduando stricto sensu com título de Doutorando em Artes e Humanidades com menção em Ciências da Educação na UNR-ARGENTINA Universidad Nacional de Rosario; Pós-graduando stricto sensu como Aluno Especial de Doutorado em Educação na FEUSP Faculdade de Educação da Universidade de São Paulo; Professor de Educação Básica I - Arte no Governo do Estado de São Paulo; Professor de Educação Básica II - Educação Artística na Prefeitura Municipal de Ferraz de Vasconcelos; Professor de Espanhol no Colégio Edukandarium Mondini; Professor convidado da Educação Superior - Artes Visuais no IMEP Educacional; Professor convidado da Educação Superior - Graduação em Artes Visuais, Pedagogia e Letras, Pós-graduação em Alfabetização e Letramento, Psicomotricidade, Neuropsicopedagogia, Neurociências no IEFE Evolução Educacional. Universidad Nacional de Rosario. http://orcid.org/0000-0002-3515-470X . Correio eletrônico: rafaclimarte@gmail.com
} 


\section{INTRODUCCIÓN}

El objetivo de esta investigación es analizar la amplitud de los conceptos de Bruner (1985) complementándolos, aunque el lenguaje es un tema muy comentado, la teoría planteada por el autor enfatiza la negociación que hacen los interlocutores del diálogo.

Más allá de la implicación de negociación, hay también la implicación de carácter bifacético del lenguaje y la implicación de cultura que involucran el lenguaje en la educación.

Sin embargo, la relevancia de esta investigación es corroborar los conceptos de Bruner (1985), considerando que, para resultar la negociación, se necesita reglas y soluciones mediadas por los interlocutores del diálogo.

Muchos conceptos que aparecen en su teoría no los profundiza, por lo que la situación problémica consiste en recolectar informaciones que tengan como base los planteos de su obra, hay preguntas no respondidas, a saber, del cómo hacer, cómo tratar, cuáles son las reglas de juego para la negociación del lenguaje.

El desarrollo de esta investigación será integrado a la tesis doctoral, que analiza los diálogos como práctica pedagógica desarrollados por los docentes y estudiantes, que tuve su proyecto de investigación aprobado por la Universidad Nacional de Rosario (UNR), desde mayo de 2019. Sin embargo, la elección del tema investigado se justifica por la importancia que Jerome Bruner (1985) hace del lenguaje de la educación, en las relaciones entre el lenguaje, el pensamiento y la socialización.

Siendo así, la investigación habla directamente con Burbules (1999) que coincide en muchas de las temáticas del autor y principalmente para establecer las reglas del juego, ya en Habermas (1976) habla del desdoblamiento de la comprensión del lenguaje, para Searle (1962) son recolectados los actos de habla y para determinar las funciones generales de las reglas del juego y por fin en Paul Grice (1989) para el desarrollo de la comunicación.

\section{EL DIÁLOGO EN LA ENSEÑANZA}

El diálogo en la enseñanza, como lo he llamado, o el lenguaje de la educación, planteado en Bruner (1985), impone necesariamente una perspectiva, que se ven las cosas y una actitud hacia lo que miramos, por eso, nunca puede ser neutral; enfatiza el lenguaje en la educación por la negociación y renegociación; y el mensaje encarna y predispone a aquellos quienes lo oyen a pensar de un modo particular con respecto a él, resume así, el lenguaje no sólo transmite, el lenguaje crea o constituye el conocimiento o la realidad.

Sin embargo, para mencionar las realidades de la sociedad y de la vida social son en casi siempre productos del uso lingüístico representado en actos de habla como, el de prometer, abjurar, legitimizar, bautizar, etc. (BRUNER, 1985, p.128).

Los "actos de habla" no son abarcados en el autor, sin embargo, tales características concernientes al lenguaje se encuentran conceptuados en Burbules (1999, p.105 apud SEARLE, 1962), siendo:

- Expresar un significado;

- Hacer una referencia; y

- Afirmar la verdad.

Según Bruner (1985, p.130 apud HALLIDAY, 1974) separa las funciones del lenguaje en dos partes:

- Pragmática - la instrumental, la reguladora, la interaccional y la personal;

- Matética - la heurística, la imaginativa y la informativa.

- La función heurística es el medio para lograr que los demás nos informen y corrijan;

- La función imaginativa es el medio con el cual creamos mundos posibles y trascendemos lo inmediatamente referencial;

- La función informativa se construye la base de una presuposición intersubjetiva: que yo tengo conocimientos que los demás no poseen.

- La metalingüística se refiere al uso que hacemos del lenguaje para examinarlo o explicarlo.

Después de presentar las funciones del lenguaje, se reconoce y se amplía la presentación de los conceptos del diálogo en la educación, que tiene por "proceso y la meta de la educación son una sola y misma cosa. La meta de la educación es el logro de la comprensión disciplinada; el proceso es lo mismo" (BRUNER, 1962, p.159).

Siendo así, para que haya "comprensión" en el lenguaje recorremos los conceptos abarcados en Burbules (1999, p.113 apud HABERMAS, 1976-1984) que discursa sobre el tema de la siguiente forma:

- Comprensibilidad - formular el enunciado de manera gramatical, clara y comprensible; 
- Verdad-seleccionar el contenido proposicional para que represente fielmente una experiencia o un hecho;

- Sinceridad - expresar las intenciones de manera que la expresión lingüística refleje fielmente lo que se quiere decir;

- Corrección - llevar a cabo un acto de habla de manera que satisfaga normas reconocidas o imágenes aceptadas.

Presentado el tema principal del autor, en secuencia, se encuentra las implicaciones del lenguaje de la educación y la charla que su teoría nos propone.

\section{IMPLICACIONES PRÁCTICAS DEL LENGUAJE DE LA EDUCACIÓN}

De forma general, el autor nos aporta, la verdad es que siempre la relación profesor-alumno estuve en riesgo, partiendo del presupuesto de que "los procesos mentales son interiorizaciones del intercambio social, un coloquio interno moldeado por anteriores diálogos externos" (BRUNER, 1962, p.151), y aún más que en la integridad, cada hombre crea su propia versión del mundo, proveniente de una herencia cultural por medio de la educación.

Sin embargo, Burbules (1999, p.107) complementa la idea que el diálogo es una actividad comunicativa en la que corremos "riesgos" y pedimos a otros que los corran junto con nosotros.

Asimismo, las implicaciones van más allá, pues "nuestra educación no está amenazada por un mal mayor que el del sentimentalismo" (BRUNER, 1962, p.150), es decir, el sentimentalismo no es lo mismo que afectividad, y sí un demasiado extrañamiento de que el lenguaje en la educación tiene doble vías o múltiples interpretaciones.

En el planteo de Bruner (1985) se observa algunas implicaciones prácticas del lenguaje desde lo más inmediato a lo más general:

La implicación de carácter bifacético del lenguaje si relacionamos la práctica de la enseñanza y el lenguaje en que el que se lleva a cabo, tenemos una implicación inmediata, que puede ser un modo de comunicación y un medio para representar el mundo acerca del cual está comunicando. Si no llega a desarrollar ningún sentido de intervención reflexiva en el conocimiento, estará actuando continuamente desde afuera, el conocimiento controlará y lo guiará (BRUNER, 1985, p.136).

La implicación de negociación - "Es una implicación más general, que es un foro para negociar y renegociar los significados y explicar la acción, como un conjunto de reglas o especificaciones para la acción" (BRUNER, 1985, p.136).

En ese contexto, para el profesor puede ampliar el tema de un enunciado llevándolo a la especulación y la negociación. Para el alumno hace parte del proceso negociador por el cual se crean y se interpretan los hechos, que lo configura como un agente elaborador de conocimientos y un receptor de la transmisión de conocimientos.

Las implicaciones de negociación puestas por Bruner (1985), es la esencia de su teoría del lenguaje, que necesita ser más conceptuada, para la comprensión y la práctica.

La Implicación de cultura² - la implicación de cultura en la práctica educativa suele otra interpretación de la cultura escolar que contradice las tradiciones de la pedagogía que provienen de otras épocas, otra concepción de autoridad, una cultura de transmisión de conocimientos y valores (BRUNER, 1985, p.128-129).

Al hablar de pertenencia a una cultura, enfatiza que "no sólo el descubrimiento y la invención sino la importancia del negociar y el compartir, en síntesis, de la creación conjunta de la cultura como objeto de la enseñanza y como paso adecuado para llegar a ser un miembro de la sociedad adulta en la cual pasamos nuestra vida". Sin embargo, "si desarrolla un sentido del self que se base en su capacidad para ahondar en el conocimiento para sus propios usos" (BRUNER, 1985, p.36).

El lenguaje de la educación, no puede ser el denominado lenguaje incontaminado de la realidad y la objetividad, debe expresar las actitudes y debe invitar a la contra actitud y en ese proceso dejar margen para la reflexión, para la metacognición (BRUNER, 1985, p.34).

Por lo tanto, el descubrimiento hará que el niño lo aprenda, incorporará su descubrimiento al mundo interior de cultura que crea para sí mismo (BRUNER,

${ }^{2}$ Cultura es la totalidad acumulada de esquemas y estructuras (TEMPORETTI, 2013), a su vez, estructuras culturales son sistemas organizados de símbolos significativos. 
1985, p.160). Esa es la finalidad de la teoría del autor, que puede ser también una implicación como hemos visto.

\section{LA NEGOCIACIÓN Y LAS REGLAS DEL JUEGO EN EL LENGUAJE}

Para el autor, la negociación, base de su teoría, dice que las principales herramientas es el lenguaje $y$ las reglas de su uso (BRUNER, 1985, p.127).

Para eso, se apunta Burbules (1999, p.104) que va a conceptuar cuáles son las reglas del juego fundantes y que otorgan coherencia, predictibilidad y continuidad, pero la hace de forma amplia para abrir espacio para la espontaneidad, la creatividad y la sorpresa, diciéndonos:

- La regla de la participación;

- La regla del compromiso;

- La regla de la reciprocidad.

A partir de las reglas encontradas se puede tramitar algunas actitudes y negociaciones en el lenguaje, con acciones y reacciones (los ejemplos son mías interpretaciones de la teoría de Burbules, 1999):

- Para la regla de la participación:

o Acción - excluir o desalientan la participación de los demás

- Reacción - hacer callar, avergonzar o gritar.

- Para la regla del compromiso:

- Acción - no iniciar el proceso dialógico con seriedad.

o Reacción - abandonan o lo dan por terminado el tema.

- Para la regla de la reciprocidad:

- Acción - exigir de los otros lo que no están dispuestos a aceptar que se exija de ellos;

o Reacción - atribuir privilegios en el encuentro comunicativo que no se extiende a los involucrados.

Dicho eso, Burbules (1999, p.105 apud SEARLE, 1962) señala dos funciones generales para las reglas del juego que se debe tener en cuenta:

- Las reguladoras - confieren orden y estructura a actividades humanas;

- Las constitutivas - definen ciertas actividades que no pueden quedarse sin ellas.

Sin embargo, apoyado en Burbules (1999, p.111 apud GRICE, 1989, p.26) las reglas del juego basadas en el principio de cooperación para el desarrollo de la comunicación son:

- Cantidad;

- Cualidad

- Relación; y

- Modo

Siendo así, los autores ejemplifican los aspectos planteados por Bruner que son pasibles a la práctica del lenguaje, por la negociación y la creación de cultura.

\section{CONSIDERACIONES}

La investigación presentó los principales conceptos desarrollados por Bruner (1985) en el lenguaje de la educación y las implicaciones o riesgos que pasan a los interlocutores, enfatizando el concepto llave del autor por la negociación entre ellos.

La complementariedad identificada en los autores a los conceptos abarcados en la teoría de Bruner (1985) apuntan aportes prácticos y directos a la práctica del lenguaje, a su vez, fueran más desarrollados en las reglas del juego que suelen favorecer los acuerdos de diálogo.

La investigación teórica, consistió en importantes hallazgos que favorecen la práctica pedagógica de los docentes que serán utilizadas en las investigaciones de la tesis doctoral, que concierne los aspectos favorecedores por las reglas del juego, los conceptos de Habermas de comprensión y en los aspectos obstaculizadores de las implicaciones planteadas por Jerome Bruner, principalmente en la negociación que hacen los interlocutores.

\section{REFERÉNCIAS}

BRUNER, J. Después de Dewey ¿Qué? In: El saber y el sentir. México: Editorial Pax México, 1962.

BRUNER, J. (1985) II. Dos modalidades de pensamiento. IX. El lenguaje de la educación. In: Realidad mental y mundos posibles. Barcelona: Gedisa, 1988.

BURBULES, N. C. El diálogo en la enseñanza: teoría y práctica. Buenos Aires: Amorrortu editores, 1999.

TEMPORETTI, F. La perspectiva de la Psicología 
Cultural en la formación de los extensionistas agropecuarios. Trabajo presentado en el 1er Congreso Latinoamericano de Psicología Rural, octubre 2013, Posadas, Misiones, Argentina.

TEMPORETTI, F. Revolver la educación. Seminario

Psicología (y) educación. UADER. UNR. UNL, 2016. 